Review

\title{
Shoot culture as plant material to study gene expression under the influence of different regeneration pathways and stress conditions in Lycopersicon esculentum Mill
}

\author{
Ahmed M. Hassanein, Galal A., Saad G. K. \\ Central Laboratory of Genetic Engineering, Sohag University, POX 82524, Sohag, Egypt.
}

Rec. 25 July, Accpt. 15 August 2010

\begin{abstract}
Shoot regeneration on cotyledon or hypocotyl explants excised from tomato seedlings and obtained from seeds germinated on MS medium without growth regulators was used to establish tomato shoot culture. Tomato regeneration was influenced by the physiological condition of the donor of explants as well as the explants type. Comparison between the morphogenesis type, SDS and native PAGEs indicated that gene expression can be used to differentiate between tomato cultivars and early determination of the differentiation type, where conditions stimulated shoot organogenesis increased the number and/or the staining intensity of peroxidase and indophenol oxidase bands as well as induced the expression of specific polypeptides. Shoot cultures were used to study gene expression under the influence of stress conditions. Increase in isoenzyme activity under the influence of relatively high concentration of $\mathrm{NaCl}$, manniol or cupper $\mathrm{CuSO} 4$ as well as high temperature treatment resulted from increase the number of isoenzyme forms and/or increase the staining intensity of some isoenzyme forms. SDS PAGEs indicated that stress conditions caused an induction or inhibition of the synthesis of some polypeptides. Shoot culture established ideal condition to study gene expression under the influence of biotic and abiotic stress factors in tomato.
\end{abstract}

Key words: Gene expression, peroxidase, indophenol oxidase, SDS PAGE, stress factors, tissue culture.

\section{Introduction}

Tomato (Lycopersicon esculentum Mill) belongs to the family Solanaceae. It is a diploid plant with $2 \mathrm{n}=24$ chromosomes. It is grown in almost every country of the world. Nowadays, tomato is grown in an area of around 3.9 millionhectares worldwide. Tomato is one of the important plants, which plays a vital role in maintaining human health, vigor and helpful in healing wounds because of the antibiotic properties found in the ripe fruit. In addition, tomato is a rich source of Vitamin C, Vitamin B, fibers and a good source of $\beta$-carotene (Raziuddin et al., 2004). Tomato fruit consists of approximately $20-50 \mathrm{mg}$ of lycopene/100 $\mathrm{g}$ of fruit weight (Kalloo 1991).
Lycopene is the carotenoid, which causes colours of fruits and vegetables. Lycopene is the most powerful antioxidant; consequently, it protects human cells from free radicals that degrade many parts of the body, and prevents cancer (Block et al., 1992; Gerster 1997; Rao and Agarwal 2000).

Development of in vitro selection can provide new procedures for the production of stress tolerant plant cultivars. Tissue culture techniques of tomato were successfully used for selection of tolerant cell lines for various biotic and abiotic stresses under laboratory conditions, as it needs comparatively less effort and fewer resources than selection of tomato genotypes using traditional procedures under field conditions.

\footnotetext{
* Corresponding author:

Dr. Ahmed M. Hassanein

$\bowtie$ hassaneinam@yahoo.com
} 
Selection of cell lines for salt and drought tolerance, has been achieved by gradual exposure of cells to stress levels in the growth medium (Srivastava et al., 1995; Hassanein 1999, 2004 ; He et al. 2009). The ability to regenerate large number of plants, in short time, at any time, from small plant material can be used to clone the genetically engineered plants (Petitprez et al., 2005) and artificial seed production (Hassanein et al., 2005; Salem 2009). The techniques have been modified and optimized for the production of economic natural plant products, haploids, somatic embryos as well as sexual and somatic hybrids. In this concern, attempts have been made to transfer the higher regenerative ability of wild varieties to cultivated tomatoes. Although, essential and valuable information become available on the tissue culture of tomato, the techniques have not been developed to a level at which they can be utilized in large-scale multiplication of commercially important cultivars (Bhatia et al., 2004).

Tissue culture systems are also used to evaluate stress tolerance at the cellular level, create genetic variation for germplasm improvement (Duncan et al., 1991), and to transfer elite genes from other plants or other living organisms to improve distinct plant species (Kresovich et al., 1987; Hagio et al., 1991).

\section{Sterilization requirements needed to establish tomato in vitro culture from seeds}

Tomato seeds of any cultivar (Cassel rock, Strain-B and Boture) can be used to establish shoot cultures. In general, seeds were surface sterilized and transferred to germinate on the culture medium. The obtained seedlings were used as a source for explants to establish tomato shoot culture. Efficient surface sterilization, was obtained when tomato seeds were treated with $5 \%$ Clorox solution [sodium hypochlorite (NaCIO)] for 5 minutes, followed by $70 \%$ ethyl alcohol for 10 minutes. The concentration as well as the duration of soaking may be reduced or increased according to the need. As long as 45 min soaking in $10 \%$ Clorox was used. Other surface disinfectants including calcium hypochlorite and mercuric chloride were used. Three rinses with sterile distilled water were applied to remove the disinfectant before seeds culturing on MS medium under tissue culture conditions (Saad 2010). Seeds tolerate relatively high concentrations of both Colorox and/or ethyl alcohol than soft plant tissues. Consequently, pure cultures could be easily established and the toxic effect of disinfection agents was avoided. In ten days, healthy-pure tomato seedlings were obtained and they were used as explant-donor material for callus induction and shoot regeneration from cotyledon, hypocotyl, and radical explants (Saad 2010).

\section{Tomato regeneration using different types of explants}

The registered differences in the regeneration potential of different organs and explants have various explanations. They include differences in the stage of the cells in the cell cycle, the ability to transport endogenous growth regulators, and the metabolic capabilities of the cells (Novak and Maskova 1979; Ancora and Sree-Ramulu 1981; Zapata et al,. 1981). Meristematic organs are the most commonly used as tissue explants, they obtained from organs such as the stem tip, auxiliary bud and root tip (Edwin et al., 2008). The tissues undergo high rates of cell division; they either concentrate or produce required growth regulating substances including auxins and cytokinins (Ferguson and James 2006). Regeneration of tomato (Lycopersicon esculentum Mill.) has been a subject of great number of researches because of its amenability for further improvement via genetic manipulation (Evans 1989, Wing et al., 1994; Hassanein et al., 1998, Fayez and Hassanein 2000; Hassanein 2004a; Saad 2010). Numerous reports on plant 
regeneration from a wide rang of explants of wild and cultivated tomato germplasm were described (Padmanabhan et al., 1974; Cassells 1979; Novak and Maskova 1979; Ancora and Sree-Ramulu 1981; Zapata et al,. 1981; Saad 2010).

Organogenesis in tomato was achieved from different explant tissues: cotyledons, stems and hypocotyls (Branca et al., 1990; Compton and Veilleux 1991; Gubis et al., 2004; Saad 2010). Tomato is one of the most studied higher plants because of its importance as a crop species, and of several advantages for genetic, molecular and physiological studies (Mccormic et al., 1986; Hassanein 1993; Wing et al., 1994; Hassanein 2004 $\mathrm{a}, \mathrm{b}$; Matoo and Handa 2008).

\section{Tomato regeneration as influenced by the physiological conditions of the donor explants and explants type}

In general, the disinfected tomato seeds were germinated on basal MS medium without growth regulators and used as plant materials to establish shoot culture. In addition, shoot culture can be established after direct or indirect regeneration from different types of explants such as cotyledons, hypocotyls or radicals obtained from ten days old seedlings. The physiological state of plant from which the explant was taken was extremely important for regeneration processes.

Explants obtained from seeds germinated on MS medium without phytohormones expressed higher regeneration response values in comparison to those germinated on MS medium supplemented with relatively high concentration of BAP (11.2 $\mathrm{mg} / \mathrm{l} \mathrm{BAP}$ ), irrespective the type of explant (Saad 2010). Under these conditions, the endogenous and exogenous BAP content of tissues of the seedlings germinated on a medium containing high BAP was not suitable for induction of tomato regeneration. The promotive effect of relatively low concentration of BAP on axillary shoot formation was reported in tomato and other plant species
(Burger, 1987; List et al., 1996; Hassanein 2004 $4_{\mathrm{a}, \mathrm{b}}$; Hassanein et al. 2008; Hassanein et al., 2009; Saad 2010).

The morphogenic response of cultured tomato tissues was affected by the chemical components of the culture media, especially the type and concentration of growth regulators (Saad 2010). When tomato explants (cotyledons, hypocotyls and radicals) were cultured on MS medium containing different hormonal treatments under light condition, they began to enlarge in 3 days of culture, expanded to a considerable size and became dark green. The cultured explants showed continuous enlargement with time. This enlargement increased in size and formed unorganized callus or initiated organ primordia depending on the light treatment and phytohormones as was reported in previous reports (Hassanein and Soltan 2000; Hassanein and Mazen 2001; Hassanein 2004 ; Saad 2010).

Regeneration of adventitious buds appeared from the enlarged explant within two weeks, and developed into normal adventitious shoots within 6 weeks of culture. The regeneration potential of explants depended on the hormonal component of the media. MS medium supplemented with 4.48 $\mathrm{mg} / \mathrm{l} \mathrm{BAP}$ was the best as it resulted in the highest number of buds capable of further development to form shoot (Figs. 1 and 2).

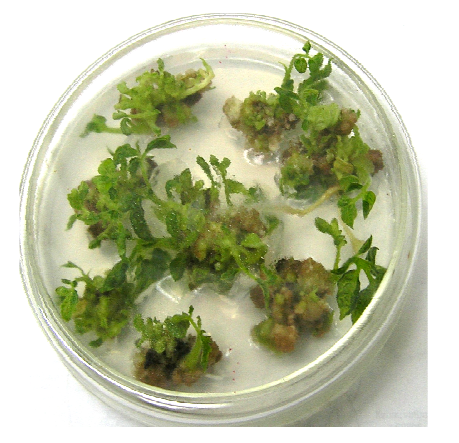

Fig. (1): Photograph showing clusters of multiple shoots on cotyledon explants after culturing on MS medium supplemented with $4.48 \mathrm{mg} / \mathrm{l}$ BAP for four weeks. 


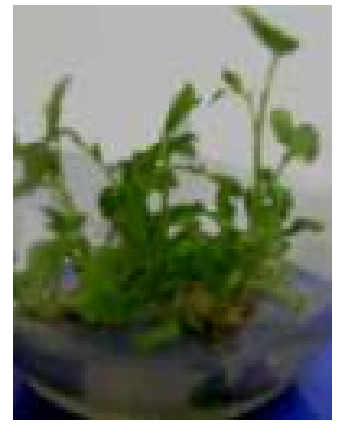

Fig. (2): Photograph showing the enhancement of normal shoots growth in glass jar containing MS medium without growth regulators for four weeks.

Regeneration frequency was reduced when BAP $(4.48 \mathrm{mg} / \mathrm{l})$ in combination with low concentration of NAA $(0.2 \mathrm{mg} / \mathrm{l})$ were used. Hassanein $\left(2004_{b}\right)$ reported that in Alhagi graecorum, the role of 2,4-D as trigger of somatic embryogenesis and BAP as trigger of adventitious bud formation was deduced, but for maximum yield, certain auxin-cytokinin ratio should be applied. In addition, endogenous and exogenous growth regulators play an important role in the needed ratio (Hassanein 2004 b).

Induction of adventitious buds from cotyledon or hypocotyls of tomato explants was recommended in our lab. These cotyledons were excised from ten days old seedlings obtained from seeds germinated on MS medium without growth regulators. Radical explants were not recommended for adventitious bud formation where, small calli were formed irrespective the type or the concentration of phytohormones. The response of different tomato cultivars expressed different values. Cassel rock cultivar is recommended to establish tomato shoot culture to study the effect of biotic and abiotic factors on gene expression.

\section{Oxidases expression of different tomato cultivars}

Studying the protein components of the SDS PAGE and isozyme patterns of peroxidases were used to differentiate between plant lines or cultivars (Takesley and Orton 1983; Ochatt et al., 2005; Hassanein et al. 2008; Sikdar et al., 2010).

The expression of peroxidase isozymes of three tomato cultivars indicated that no variation could be detected among Strain-B, and Boture cultivars. Although, three peroxidase bands (POX-2, POX-3 and POX-6) were not detected in Cassel rock cultivar but they were detected in the other two cultivars (Fig. 3).

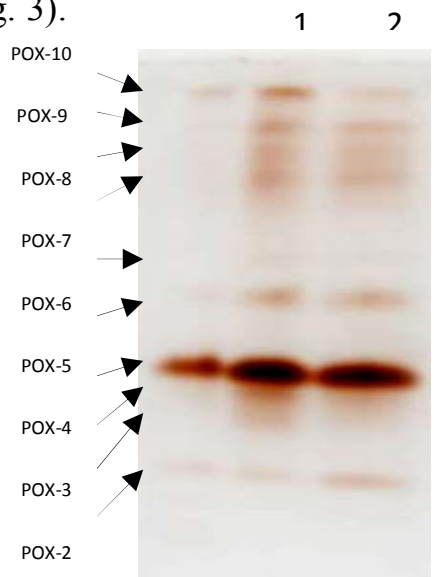

Fig. (3): Native gel electrophoresis of POX isoenzymes in shoots of the three tomato cultivars. Lane 1: Cassel rock, Lane 2: Strain-B, Lane 3: Boture.

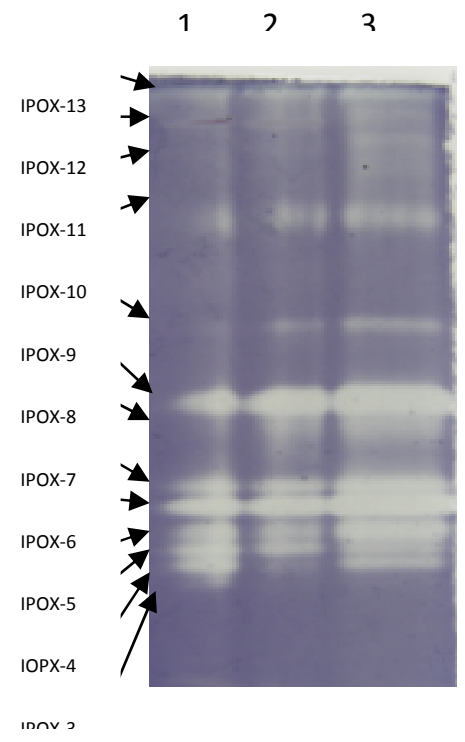

Fig. (4): Native gel electrophoresis of IPOX isoenzyme in shoots of the three tomato cultures. Lane 1: Cassel rock, Lane 2: Strain-B, Lane 3: Boture. 
On the other side, indophenol oxidase expression can be used to differentiate between tomato cultivars, one new indophenol oxidase band (IPOX-1) was detected in Cassel rock cultivar, four new indophenol oxidase bands (IPOX-7, IPOX-9, IPOX-11 and IPOX-12) were detected in Strain-B, and Boture shoots (Fig. 4). Studying of these enzymes is very important because phenol oxidases as antioxidants use phenolic compounds to detoxify reactive oxygen species (Elstner and Osswald 1994). Antioxidants play an improvement role in proliferation and regeneration ability in diverse plant species (Benson and Roubelakis-Angelakis, 1994; Elstner and Osswald 1994; Foyer et al., 1994; Poolle 1995). A parallel relation between the synthesis of phenolic compounds and phenol oxidases as well as regeneration ability was also reported by Nicholson and Hammerschmidt (1992) and Hassanein (1999). Cassel rock is recommended to study the influence of stress conditions on gene expression under in vitro conditions because it expressed the highest response to the used culture condition (Saad 2010).

\section{Gene expression in stem explants under the influence of different regeneration pathways}

It is well known that isoenzymes are organspecific; their expression is usually developmentally controlled. A change in the isoenzyme pattern of any particular organ during a particular phase of development was marked by the appearance or disappearance of the isoenzyme form. Such changes in isoenzyme expression suggest that the genes involved in the synthesis of these isoenzymes are differentially activated during development (Chawla 1991). Gene expression of tomato plant (Cassel rock) under the influence of different differentiation pathways was studied using native and SDS PAGEs. Induction of bud formation was fulfilled on MS medium supplemented with $4.48 \mathrm{mg} / \mathrm{l} \mathrm{BAP}$; induction of callus formation was accomplished on MS medium supplemented with $2 \mathrm{mg} / \mathrm{l} \mathrm{BAP}+0.2$ $\mathrm{mg} / \mathrm{l}$ NAA; but induction of root initiation was fulfilled on MS medium supplemented with $1 \mathrm{mg} / 1$ IBA (Saad 2010).

Comparison between the morphogenesis data and the isoenzyme patterns indicated that conditions stimulated shoot organogenesis increased the number and/or the staining intensity of peroxidase and indophenol oxidase bands. Increasing the staining intensity of POX bands under conditions stimulating adventitious bud formation in comparison to those stimulating callus or root formation gave indication about increase of the peroxidase activity prior to adventitious bud formation.

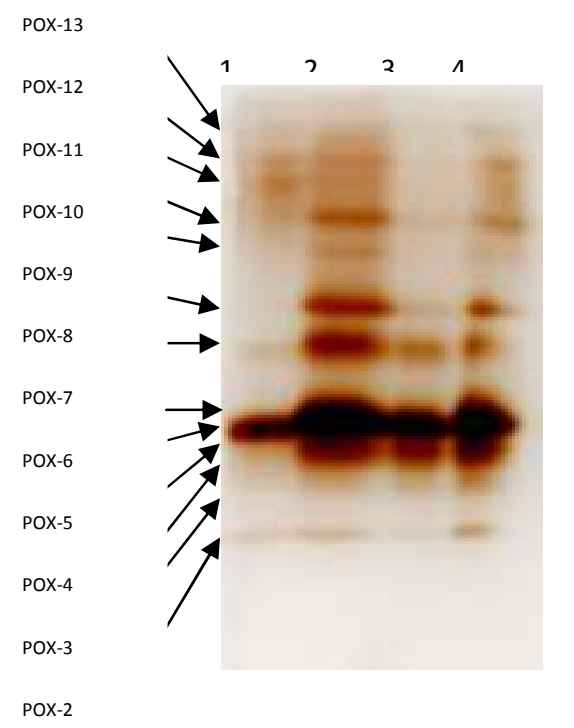

Fig. (5): Native gel electrophoresis of POX isoenzyme during culture of stem explants for seven days on bud initiation medium (Lane 2), callus induction medium (Lane 3), and root initiation medium (Lane 4) in comparison to those cultured on hormone-free medium (Lane 1) as a control.

The intensity of isoenzyme bands gives indication about the activity of these isoenzymes as was reported previously (Khavkin and Zabrodina 1994; Hassanein 1998; Hassanein et al., 2009). In this concern, new POX bands were detected during the tendency of tomato tissue to 
form adventitious buds. Increase in peroxidase activity automatically accentuated auxin catabolism, resulting in lowering endogenous auxin level. Consequently, an optimal auxin/cytokinin ratio favors the formation of adventitious buds.

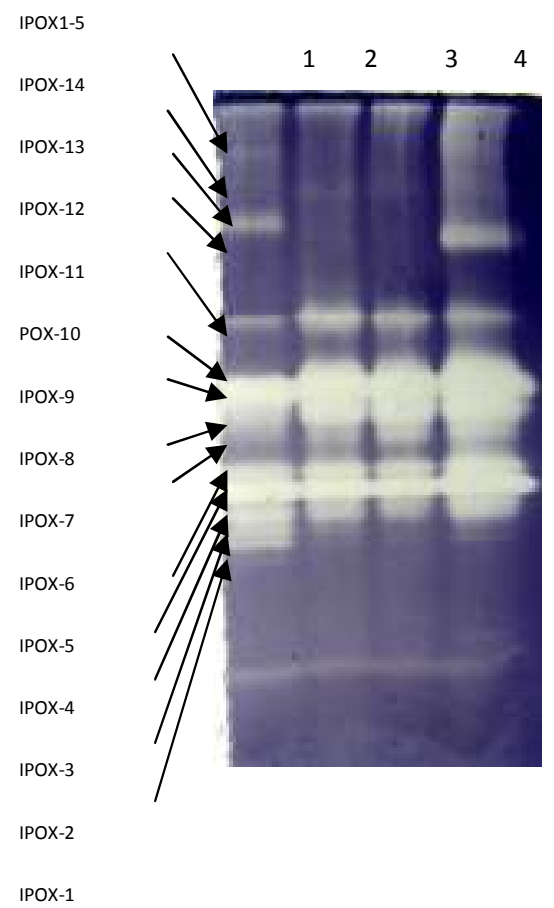

Fig. (6): Native gel electrophoresis of IPOX isoenzyme during culture of stem explants for seven days on bud initiation medium (Lane 2), callus induction medium (Lane 3), and root initiation medium (Lane 4) in comparison to those cultured on hormone-free medium (Lane 1) as a control.

Callus formation resulted in a decreased in the number and staining intensity of several POX bands in comparison to POX expression under the influence of root or shoot formation (Fig. 5). In general, conditions stimulating callus formation expressed the lowest number of peroxidase bands and relative peroxidase activity, as was reported in other reports (Wakamatsu and Takahama 1993; Hassanein $2004_{a}$ ). It may be due to the nature of this plant material, as it was characterized by high pressure and low osmotic potential (Hassanein $\left.2004_{\mathrm{a}}\right)$.

IPOX expressed distinct pattern when the tomato stem cuttings were cultured under conditions stimulating root formation (Fig. 6), where a new IPOX band was detected (Saad 2010). The capacity of phenolic compounds to act as auxin synergists during root formation is well known (Hu and Wang 1984). Elstner and Osswald (1994) reported that de novo synthesized phenols and indophenols oxidase play an important role as antioxidants and regulators of enzyme activities. These processes may be enhanced also during root and callus formation of tomato. The capacity of phenolic compounds to promote root formation is known and depends on plant species (Hassanein et al. 1999). The presence of leaves and shoot tips as a system for the regulation of endogenous hormones and as a receiver of light was very important for the root organogenesis. This suggests that the light-induced synthesis of phenolic compounds, which synergised the role of IBA in the root formation (Hassanein et al. 1999). The stimulation of root growth under light conditions may be due to the reduction in the auxin concentration, which may in turn be due to the oxidation of auxin under illumination conditions.

The regeneration potential of the cultured tissue was dependent on both scavenging potential and the ability to produce $\mathrm{H}_{2} \mathrm{O}_{2}$ through NADH-POX activity. Phenol oxidases use phenolic compounds to detoxify reactive oxygen species (Nicholson and Hammerschmidt 1992; Benson and RoubelakisAngelakis 1994; Elstner and Osswald 1994). Under light conditions, phenol oxidizing enzymes may prevent the accumulation of a toxic concentration of $\mathrm{H}_{2} \mathrm{O}_{2}$ and consequently enhance the organogenesis of the cultured tomato tissues as was reported in other plant species (McComb and Newton 1981; Hassanein and Mazen 2001; Koca et al., 2007; Athar et al., 2008).

SDS PAGE pattern of Cassel rock stem cuttings under the influence of the three differentiation conditions for seven days indicated 
that, one new polypeptide with molecular weight of $36.5 \mathrm{KDa}$ was detected during bud and root initiation conditions, but it was not appeared in plant materials cultured on callus induction medium. In addition, the staining intensity of a polypeptide band with a molecular weight of 31.5 KDa increased in plant materials subjected to bud initiation conditions (Saad 2010). Comparison between native and SDS PAGEs indicated that staining for specific isoenzymes was recommended than SDS PAGEs to differentiate between tomato cultivars and early determination of the regeneration type.

It becomes clear that peroxidases respond dramatically to multiform environmental stresses (Andreeva 1988; Gaspar et al., 1991). The cells obtained from different organs when grew in tissue culture and exposed to identical conditions, they developed a uniform pattern of isoenzymes (Watanabe et al., 1994). In addition, this enzyme system has been used as a model to study hormonal control of growth and morphogenesis processes in plants (Galston and Davies 1969).

\section{Alteration in gene expression of tomato cultivars under the influence of different stress factors}

Plant tissue culture has been proposed as a useful, quick and economical tool for evaluating the stress tolerance via shoot organogenesis from leaf explants, and the shoot apex growth (Mercado et al., 2000). Because the activated oxygen is toxic, it has to be under strict control of detoxification processes, eg. detoxificating enzymes. This may be achieved by activation of isoenzymes such as peroxidases. Consequently, studying peroxidase, indophenol oxidase is an important step towards understanding the effect of abiotic stress on tomato plant (Hassanein 1998, 1999, 2004b). Peroxidase isoenzymes have been investigated more than any other plant isoenzyme because of their common occurrence and the ease of their detection (Scandalios 1974; Hassanein
1993, 1998, 2004 $a, b)$.

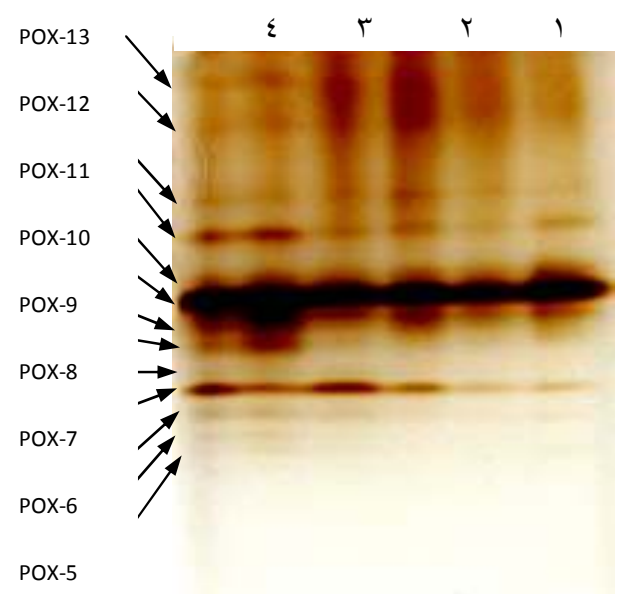

Fig. (7): Native gel electrophoresis of POX isoenzyme of tomato shoots under the influence of different concentrations of $\mathrm{NaCl}$. Lane 1: Cassel rock shoots on basal MS medium (control); Lanes 2, 3, 4, 5 and 6: Cassel rock shoots subcultured on MS media supplemented with 50,100,150,200, and $250 \mathrm{mM}$ $\mathrm{NaCl}$ for two weeks respectively.

The alteration of gene expression in shoots of three tomato cultivars under the influence of relatively high salt concentration $(250 \mathrm{mM}$ of $\mathrm{NaCl}$ ) for two weeks was studied using native and SDS PAGEs (Saad 2010). The used three tomato cultivars expressed different response to relatively high $\mathrm{NaCl}$ concentration. In general, the staining intensity of the peroxidase bands increased when the plant shoots were subcultured on MS medium containing relatively high $\mathrm{NaCl}$ concentration (250 $\mathrm{mM}$ ). The number and density of IPOX bands and staining intensity of IPOX bands increased when the used tomato cultivars were subjected for relatively high concentrations of $\mathrm{NaCl}$ (Fig. 7). SDS PAGEs indicated that subjecting tomato shoots to relatively high $\mathrm{NaCl}$ concentration resulted in an expression of new polypeptides with molecular weights of $36,70,73,85,135$ and 150 KDa (Saad 2010).

Peroxidase and indophenol oxidase activities increased when the tomato cultivars were subjected for high cupper concentration in culture 
media (Saad 2010). The registered increase of the enzyme activity was illustrated by the increase in the staining intensity of bands of both visualized isoenzymes (Khavkin and Zabrodina 1994, Hassanein 1998, 2004 ${ }_{\mathrm{a}, \mathrm{b}}$, Hassanein et al., 2009). SDS PAGE analysis indicated that expression of polypeptide with molecular weight of $110 \mathrm{KDa}$ was detected in the studied tomato cultivars when they were subcultured on MS medium supplemented with $7.85 \mathrm{mg} / \mathrm{l} \mathrm{CuSO} 4$ (Saad 2010). Heavy metal at higher concentration, as other environmental stresses triggers a wide range of cellular responses including changes in gene expression and synthesis of detoxifying polypeptides (Xiang and Oliver 1998; Suzuki et al., 2001; Louie et al., 2003).

The effect of relatively high temperature on gene expression of three tomato cultivars was studied (Saad 2010). The used three tomato cultivars expressed different peroxidase pattern under the influence of high temperature $\left(40{ }^{\circ} \mathrm{C}\right)$. High temperature condition caused an induction or inhibition in the synthesis of some polypeptides in the shoots of tomato plants. Extreme temperature reduces the rate of photosynthesis by lowering the activity of enzymes involved in $\mathrm{CO} 2$ assimilation (Martin and Herbert 1983). In addition, temperature interacts with light to control photorespiration and photoreduction of oxygen resulting in the formation of elevated concentration of $\mathrm{H}_{2} \mathrm{O}_{2}$. The rate of photoreduction of oxygen is increased with increasing light intensity, reaching saturation at a light intensity similar to or even lower than that required for maximum photosynthetic electron transport (Hodgson and Raison 1991; Poolle 1995; Heber et al., 1996). Photoreduction of oxygen is enhanced by extreme heat stress, especially if the stress condition decreases $\mathrm{CO}_{2}$ assimilation and it needs detoxification through detoxification enzymes such as peroxidases. It explains the increase of activity of peroxidases under stress.
Native and SDS PAGEs indicated that gene expression of tomato cultivars was influenced by water stress resulted from mannitol in growth medium. Staining intensities of peroxidase isoenzyme forms increased with the increase of mannitol concentration $(300 \mathrm{mM})$. Regeneration and gene expression of drought-ensitive Lycopersicon esculentum under different concentrations of mannitol were studied (Hassanein 2004b). Peroxidase activity increased under drought stress conditions, where new isoenzyme forms of peroxidase were detected. When plants experience water deficits, stomatal pores close (Lawlor and Cornic 2002; Saccardy et al., 1996; Tezara et al., 1999) leads to decreases in photosynthetic $\mathrm{CO}_{2}$ assimilation due to restricted diffusion of $\mathrm{CO}_{2}$ into the plant leaves (Pelleschi et al., 1997). Closure of stomata as a result of water deficit and consequent decrease in $\mathrm{CO}_{2}$ concentration in the leaf mesophyll resulted in the accumulation of NADPH in the chloroplasts. This situation resulted in decreasing the cell content of NADP. Consequently, $\mathrm{O}_{2}$ acts as an alternative electron acceptor resulting in the formation of superoxide radical (Gamble and Burke 1984; Baisak et al., 1994; Sairam et al., 1998) leading to oxidative stress.

\section{References}

Ancora, G. and Sree-Ramulu, K. (1981): Plant regeneration from in vitro cultures of stem internodes in self-incompatible triploid Lycopersicon peruvianum Mill. and cytogenetic analysis of regenerated plants. Plant Sci. Lett. 22: 197-204.

Andreeva, V. A. (1988): Ferment Peroksidaza. Uchastie Zashchitnom Mekhanisme Rastenii (The Enzyme Peroxidase: Its Participation in Plant Defense Mechanisms), Moscow. Nauka.

Athar, H.; Khan, A., and Ashraf, M. (2008): Exogenously applied ascorbic acid alleviates salt-induced oxidative stress in wheat. Environ. Exp. Bot. 63: 224-231.

Baisak, R., Rana, D. P. B. and Kar, M. (1994): 
Alterations in the activities of active oxygen scavenging enzymes of wheat leaves subjected to water stress. Plant Cell Physiol. 35: 489-495.

Benson, E. E. and Roubelakis-Angelakis, K. (1994): Oxidative stress in recalcitrant tissue culture of grapevine. Free Radical Biol. \& Med. 10: $355-$ 362.

Bhatia, P., Nanjappa, A., Tissa, S. and David, M. (2004): Tissue culture studies of tomato (Lycopersicon esculentum). Plant Cell, Tissue and organ Culture. 78: 1-21.

Block, G. B., Patterson, B. and Subar, A. (1992): Fruits, vegetables and cancer prevention: a review of the epidemiological evidence. Nutr. Cancer 18: 1-29.

Branca, C., Torelli, A. and Bassi, M. (1990): Effects of benzisoxazole and benzisothiazole on tomato plant regeneration in vitro. Plant Cell Tiss. Org. Cult. 21: 17-9.

Burger, W. D. (1987): In vitro micropropagation of Eucalyptus sideroxy. HortScience. 22: 496-497.

Compton, M. E. and Veilleux, R. E. (1991): Shoot, root and flower morphogenesis on tomato inflorescence explants. Plant Cell Tissue Organ Cult. 24: 223-231.

Cassells, A. (1979): The effect of 2, 3, 5-triiodobenzoic acid on calogenesis in callus cultures of tomato and pelargonium. Physiol. Plant. 37: 239-246.

Chawla, H. S. (1991): Regeneration potentiality and isoenzyme variation during morphogenesis of barely callus. Biologia Plantarum. 33: 175-180.

Duncan, R. R.; Waskom, R. M.; Miller, D. R.; Voiget, R. L.; Hanning, G. K; Timm, D. A. and Nabors, M. W. (1991): Registration of Gac 103 acid-soil tolerant Hegari regenerant. Crop Sci. 31: 13-96.

Edwin, F. G., Michael, A. H. and Geert, J. D. (2008): Plant Propagation by Tissue Culture 3rd Edition. 1: 1-28.

Elstner, E. F. and Osswald, W. (1994): Mechanisms of oxygen activation during plant stress. Proc. Roy. Soc. Edinburgh. 102: 131-154.

Evans, D. A. (1989): Somaclonal variation - genetic basis and breeding applications. Trends Genet. 5: 46-50.

Fayez, K. A. and Hassanein, A. M. (1999): Some aspects of incompatibility between chloroplasts and nucleus in cybrid plants containing Solanum tuberosum plastome and Solanum nugrum genome. The first Int. Conf. In Egypt on Plant Tissue Culture and Its Application, Zagazig Univ, Egypt. pp:133-143.

Ferguson L. and James, E. L. (2006): Agricultural Medicine. A Practical Guide, Springer New York. $156-166$

Foyer, C., Lelandais, M. and Kunert, K. J. (1994): Photooxidative stress in plants. Physiol. Plant. 92: 696- 717.

Galston, A. W. and Davies, P. J. (1969): Hormonal regulation in higher plants. Science. 163: 12881297.

Gamble, P. E. and Burke, J. J. (1984): Effect of water stress on the chloroplast antioxidant system I. Alterations in glutathione reductase activity. Plant Physiol. 76: 615-621.

Gaspar, T.; Penel, C.; Hagege, D. and Greppin, H. (1991): Peroxidases in plant growth, differentiation, and development processes. In: J. Lobarzewski (eds.) biochemical, molecular and physiological aspects of plant peroxidases. Univ. de Geneve., pp 249.

Gerster, H. (1997): The potential role of lycopene for human health. J. Am. College Nutr. 16: 109-126.

Gubis, J., Lajchova, Z., Farago, J. and Jurekova, Z. (2004): Effect of growth regulators on shoot induction and plant regeneration in tomato (Lycopersicon esculentum Mill.). Biologia, Bratislava. 59/3: 405-408.

He, S.; Han, Y.; Wang, Y.; Hong Zhai, H. and Liu, Q. (2009): In vitro selection and identification of sweetpotato (Ipomoea batatas (L.) Lam.) plants tolerant to $\mathrm{NaCl}$. Plant Cell, Tissue and Organ Culture. Volume 96: 69-74

Hodgson, R. M. and Raison, J. K. (1991): Superoxide production by thylakoids during chillin and its implication in the susceptibility of plants to chilling-induced photoinhibition. Planta. 183: 222-228.

Hagio, T., Blowers, A. D. and Earle, E. D. (1991): Stable transformation of Sorghum cell cultures after bombardment with DNA-coated microjectiles. Plant Cell Reports. 10: 260-164.

Hassanein, A. M. (1993): Protoplast fusion with particular emphasis to the fates of plastids. - 
Ph.D. Thesis. Assuit University, Sohag.

Hassanein, A. M. 1998: Isoenzyme patterns of Solanum nigrum and the cybrid plant containing $S$. nigrum genome and $S$. tuberosum plastome. Biologia Plantarum. 40: 617- 621.

Hassanein, A. M., Fayez, K.A. and Ahmed-Hamad, A. M. (1998): Physiological studies on nuclearorganelle interaction of cybrid plants containing Solanum nigrum genome and Solanum tuberosum plastome. Phyton 37: 167-179.

Hassanein, A. M. (1999): Alternation in protein and esterase patterns of peanut plants in response to salinity stress. Biologia Plantarum. 42: 241- 248.

Hassanein, A. M., Ahmed, A. M., Abdel-Hafez A. I. I. and Soltan, D. M. (1999): Phenol oxidizing isoenzymes and malate dehyderogenases patterns, and organogenesis of Solanum nigrum L. as affected by light treatments. Acta Agronomica Hungarica 47:127-136.

Hassanein, A. M. and Soltan, D. M. (2000): Solanum nigrum is a model system in plant tissue and protoplast cultures. Biologia plantarum. 34: 501 509.

Hassanein, A. M. and Mazen, A. M. A. (2001): Adventitious bud formation in Alhagi graecorum. Plant Cell, Tiss. Org. Cult. 65: 3135.

Hassanein, A. M. (2004a): Hormonal requirement induced different regeneration pathways in Alhagi graecorum. J. Plant biotech. 6: 171-179.

Hassanein, A. M. (2004b): Effect of relatively high concentration of mannitol and sodium chloride on regeneration and gene expression of stress tolerant (Alhagi graecorum) and stress sensitive (Lycopersicon esculentum L.) plant species. Bulg. J. Plant Physiol. 30: 19-36.

Hassanein, A. M., Ibrahiem, I. A., Galal, A. A. and Salem, M. M. J. (2005): Micro-propagation factors essential for mass production of synthetic seeds in banana. J. Plant Biotechnol. 7 (3): 175181.

Hassanein, A. M., Ahmed, A. M. and Soltan, D. M. (2008): Study of somaclonal variation and gene expression as influenced by long term culture in sorghum. Current Openion In Biotechnology 4: 13- 20 .
Hassanein, A. M., Ahmed, A. M. and Soltan, D. M. (2009): Effect of storage conditions on conservation of storage shoot tips in calcium alginate beads. Journal of Environmental Studies 1: $1-7$.

Heber, U., Bligny, R., Streb, P. and Douce, R. (1996): Photorespiration is essential for the protection of the photosynthetic apparatus of $\mathrm{C} 3$ plants against photoinactivation under sunlight. Botanica Acta. 109 (4): 307-315

Hu, C. Y. and Wang, P. J. (1984): Meristem, shoot tip, and bud culture. In: D. A. Evans, W. R. Sharp, P. V. Ammirato, Y. Yamada (eds.) Handbook of Plant Cell Cullure. Macmillan Inc., New York, London. 177-287.

Koca, H., Bor, F. O. and Turkan, I. (2007): the effect of salt stress on lipid peroxidation, antioxidative enzymes and proline content of sesame cultivars. Environ. Exp. Bot. 60: 344-351.

Kalloo, G. (1991): Introduction. In: G. Kalloo (eds.) Monographs on theoretical and applied genetics, Genetic improvement of tomato. Springer, Verlag, Berlin, Heidelbcrg, New York, 14: 1-9.

Khavkin, E. E. and Zabrodina, M. V. (1994): Heritable variation in peroxidase and esterase isoenzyme patterns of maize somaclone. Fiziol. Rast. 14: 754-761

Kresovich, S., McGee, R. E., Panella, L., Reilley, A. A. and Miller, F. R. (1987): Application of cell and tissue culture techniques for the genetic improvement of sorghum (Sorghum bicolor (L.) Moench: Progress and Potential. Advances in Agronomy. 41: 147-171.

Lawlor, D. W. and Cornic, G. (2002): Photosynthetic carbon assimilation and associated metabolism in relation to water deficits in higher plants. Plant Cell Environ. 25: 275-294.

List, S. E., Brown, P. H., Low, C. S. and Walsh, K. B. (1996): A micropropagation protocol for Melaleuca alternfolia (tea tree). Aust. J. Exp. Agri. 36: 755-760.

Louie, M., Kondor, N. and Dewitt, J. G. (2003): Gene expression in cadmium tolerant Datura innoxia detection and characterization of cDNAs induced in response to Cd. Plant Mol Biol. 52: 81-89. 
Martin, P. N. G. and Herbert Z. E. (1983): Temperature dependence of vegetative growth and dark respiration: A mathematical model. Plant Physiol. 71: 562-567.

Matoo, A. and Handa, A. (2008): Higher polyamines restore and invigorate metabolic memory in ripening fruit. Plant Sci. 174: 386-393.

McComb, J. A. and Newton, S. (1981): Propagation of Kangaroo paws using tissue culture. J. Hort. Sci. 56: $181-183$.

Mccormick, S., Niedermeyer, J., Fry, J., Branason, A., Horsch, R. and Fraley, R. (1986): Leaf disc transformation of cultivated tomato ( $L$. esculentum) using Agrobacterium tumefaciens. Plant Cell Rep. 5: 81-84.

Mercado, J. A., Sancho-Carrascosa, M. A., JimenezBermudez, S. (2000): Assassent of in vitro growth of apical stem sections and adventitious organogenesis to evaluate tolerance in cultivated tomato. Plant Cell, Tissue and Organ Culture. 62: 101-106.

Nicholson, R. L. and Hammerschmidt, R. (1992): Phenolic compounds and their role in disease resistance. Annu Rev Phytopathol. 30: 369-389.

Novak, F. J. and Maskova, I. (1979): Apical shoot tip culture of tomato. Sci. Hort. 10: 337-344.

Ochatt, S. J., Delaitre, C., Lionneton, E., Huchette, O., Patat-Ochatt, E. M. and Kahane, R. (2005): Growth, Quality and Biotechnology. In: R. Dris (eds.) WFL Publisher, Meri-Rastilan tie 3c, 00980 Helsinki, Finland Pp, 1038-1067.

Padmanabhan V., Paddock E. F. and Sharp W. R. (1974): Plantlet formation from in vitro from Lycopersicon esculentum leaf callus. Can. J. Bot. 52: 1429-1432.

Pelleschi, J., Schlagnhaufer, C. D. and Arteca, R. N. (1997): Ozone-induced oxidative stress: mechanisms of action and reaction. Physiologia Plantarum. 100: 264-273.

Petitprez, M., Sarra, A., Flores, B. E., Xuhan, X., Briere, C. and Gentzbittel, L. (2005): Somatic embryogenesis by liquid culture of epidermal layers in sun flower from genetic control to cell development. Plant Cell, Tissue and Organ Culture. 81: 331-337.

Poolle, A. (1995): Mehler reaction Friend or foe in photosynthesis. Bot. Acta. 109: 84-89.

Rao, A. and Agarwal, S. (2000): Role of antioxidant lycopene in cancer and heart disease. J. Am. College Nutr. 19: 563-569.

Raziuddin, S. S., Chaudhary, H. J., Mohammad, T. and Ali, S. (2004): Hormonal effect on callus induction in tomato. Sarhad J Agri. 20: 223-225.

Saad, G. K. (2010): Peroxidase expression under the influence of stress conditions. MS.C thesis, Sohag University, Egypt.

Saccardy, K., Cornic, G., Brulfert, J. and Reyss, A. (1996): Effect of drought stress on net CO2 uptake by Zea leaves. Planta. 199: 589-595.

Sairam, R. K., Deshmukh, P. S. and Saxena, D. C. (1998): Role of antioxidant systems in wheat genotypes tolerance to water stress. Biol. Plant. 41: 387-394.

Salem, M. M. J. (2009): "Micro-propagation factors essential for mass production of synthetic seeds in banana". PhD. Thesis, Sohag University.

Scandalios, J. G. (1974): Isoenzymes in dvelopment and differentiation. Annual Rev. of Plant Physiology. 25: 225- 258.

Sikdar, B., Bhattacharya, M., Mukherjee, A., Banerjee, A., Ghosh, E., Ghosh, B. and Roy, S.C. (2010): Genetic diversity in important members of Cucurbitaceae using isozyme, RAPD and ISSR markers. Biol. Plant. 54: 135-140.

Srivastava, D. K.; Gupta, V. K. and Sharma, D. R. (1995): in vitro selection and characterization of water stress tolerant callus cultures of tomato (Lycopersicon esculentum L.). Indian J. Plant Physiol. 38: 99-104.

Suzuki, N., Koizumi, N. and Sano, H. (2001): Screening of cadmium-responsive genes in Arabidopsis thaliana reveals protein denaturation and oxidative stresses to be critical components of cadmium toxicity. Plant Cell Environ. 24: 1177-1188.

Takesley, S. D. and Orton, T. J. (1983): Isoenzymes in Plant Genetics and Breeding, Part A. Elsvier Science Publishers BV, Amsterdam.

Tezara, W., Mitchel, V. J., Driscoli, S. D. and Lawlor, D. W. (1999): Water deficit inhibits plant photosynthesis by decreasing coupling factor and 
ATP. Nature (London). 401: 914-917.

Wakamatsu, K. and Takahama, U. (1993): Changes in peroxidase activity and peroxidase isoenzyme in carrot callus. Physiol. Plant. 88: 167-171.

Watanabe, M., Nakayama, H., Watanabe, Y. and Shimada, N. (1994): Mechanical slicing-induced alteration of GDH isoenzyme patterns, in Brassica napus leaf protoplasts. Plant Physiol. 143: 87-91.

Wing, R. A., Zhang, H. B. and Tanksley, S. D. (1994): Map-based cloning in crop plants: tomato as a model sysytem. I. Genetic and physical mapping of jointless. Mol. Gen. Genet. 242: 681688.

Xiang, C. and Oliver, D. J. (1998): Glutathione metabolic genes coordinately respond to heavy metals and jasmonic acid in Arabidopsis. Plant Cell. 10(9): 1539-1550.

Zapata, F. J., Sink, K. C. and Cocking, E. C. (1981): Callus formation from leaf mesophyll protoplasts of three Lycopersicon species: L. esculentum. cv. Walter. L. pimpinillifolium and L. hirsutum Plant Sci. Lett. 23: 41-46. 